\title{
Use of $\beta$-glucan from spent brewer's yeast as a thickener in skimmed yogurt: Physicochemical, textural, and structural properties related to sensory perception
}

\author{
Vassilios Raikos, ${ }^{1}$ Shannon B. Grant, Helen Hayes, and Viren Ranawana \\ Rowett Institute, University of Aberdeen, Aberdeen, AB25 2ZD, Scotland
}

\begin{abstract}
Powdered $\beta$-glucan extracted from brewer's yeast (Yestimun, Leiber GmbH, Bramsche, Germany) was incorporated into skimmed-milk yogurt at varying concentrations $(0.2-0.8 \% \mathrm{wt} / \mathrm{wt})$ to investigate its potential application as a thickener. The effect of $\beta$-glucan fortification on the nutritional profile, microstructure, physicochemical properties, and texture of freshly prepared yogurts was investigated. Sensory evaluation was also conducted and was correlated with instrumental analysis. The addition of Yestimun significantly reduced the fermentation time of the yogurt mix from $4 \mathrm{~h}$ to 3 h. Scanning electron microscopy revealed that $\beta$-glucan particles formed small spherical clusters within the yogurt matrix. The majority of the physicochemical properties (syneresis, viscosity, color, and titratable acidity) remained unaffected by the incorporation of Yestimun in the recipe. Textural properties showed a gradual increment with increasing $\beta$-glucan concentration. Hardness, total work done, adhesive force, and adhesiveness increased by 19.27, 23.3, 21.53, and $20.76 \%$, respectively, when using the highest amount of Yestimun powder. Sensory analysis $(\mathrm{n}=40)$ indicated that fortifying yogurt with Yestimun at $0.8 \%$ (wt/wt) concentration may affect overall acceptance ratings, which was attributed to adverse flavor and aftertaste effects. However, the overall liking score of the yogurt (5.0/9.0) shows potential for commercialization of the product.
\end{abstract}

Key words: yogurt, $\beta$-glucan, brewer's yeast, thickener

\section{INTRODUCTION}

Yogurt is a popular dairy product traditionally made by the lactic acid fermentation of liquid milk. Natural yogurt is considered to be a healthy food with beneficial

Received December 8, 2017

Accepted March 20, 2018.

${ }^{1}$ Corresponding author: v.raikos@abdn.ac.uk effects on human health (Granato et al., 2010; Tripathi and Giri, 2014). Its nutritional value is owed to the nutrients present in milk used as starting material, with cow milk being the predominant milk type used for yogurt manufacturing across the world (Chandan and O'Reil, 2006). In addition, yogurt contains lactic acid bacteria, which are essential for fermentation, and is therefore widely accepted as a probiotic product. The Food and Agriculture Organization of the United Nations/World Health Organization Working Group defined probiotics as "live microorganisms which when administered in adequate amounts confer a health benefit on the host" (FAO/WHO, 2001). This definition is widely accepted and adopted by the International Scientific Association for Probiotics and Prebiotics (Hill et al., 2014).

The macronutrient composition of milk, in particular the fat content, is a major determinant of the sensory qualities of yogurt. Dietary fats contribute to the flavor, appearance, and texture of foods and, as a result, have a positive effect on consumer liking and acceptance (Folkenberg and Martens, 2003). On the other hand, consumers are becoming increasingly aware of the scientific evidence linking high-fat diets and the development of chronic diseases such as obesity, diabetes, cancer, and cardiovascular diseases (Astrup et al., 2008; Willett, 2013). Thus, although creaminess and thickness are desired attributes for yogurt based on consumer preferences, there is an increasing demand for products that have little to no fat present in the formulation.

Recently, dietary fiber has been gaining popularity as a food ingredient in various food formulations. The beneficial effect of fiber on human health is attributed to a certain extent to its prebiotic effects. As a result, food manufacturers are keen to identify ways to include these nondigestible food ingredients in their products (Lam and Cheung, 2013). A few attempts to introduce dietary fiber in dairy products have been documented and include konjac glucomannan (Dai et al., 2016), date fiber (Balthazar et al., 2016), chitosan (Seo et al., 2009), inulin (Balthazar et al., 2015), xylooligosaccharides (Ferrão et al., 2018), and galactooligosaccharides 
(Balthazar et al., 2015; Belsito et al., 2017). $\beta$-Glucans are a type of dietary fiber isolated from a variety of natural sources such as oats, yeast, bacteria, algae, barley, and mushrooms (Ahmad et al., 2012; Zhu et al., 2015). $\beta$-Glucans are D-glucose monomers linked through $\beta$-glycosidic bonds, and their structure, molecular weight, and functionality largely depend on the source of origin as well as the method used for extraction and purification (Zhu et al., 2016). Spent brewer's yeast (Saccharomyces cerevisiae), which is known to be rich in $\beta$-glucans, is a by-product of beer manufacture produced in huge amounts (Aimanianda et al., 2009). The European Food Safety Authority (EFSA) has approved the inclusion of yeast $\beta$-glucans as a new ingredient in food formulations and recommends a portion ranging between 50 and $200 \mathrm{mg}$ per serving (EFSA Panel on Dietetic Products, Nutrition, and Allergies, 2011).

Recent research has indicated the potential of $\beta$-glucans from spent brewer's yeast as a thickening, water-holding, or oil-binding agent and emulsion stabilizer for food applications (Thammakiti et al., 2004). Furthermore, a few attempts to modify the properties of food products such as bread and mayonnaise with yeast $\beta$-glucans have been documented (Worrasinchai et al., 2006; da Silva Araújo et al., 2014; Martins et al., $2015)$. To the best of our knowledge, there is no report in the literature on the use of yeast $\beta$-glucans as a functional ingredient in yogurt. The objective of this study was to assess the potential of a commercially available $\beta$-glucan powder (Yestimun) manufactured from spent brewer's yeast as a thickening agent in skimmed yogurt. The effects of $\beta$-glucan inclusion on the yogurt gel formation during the fermentation process was monitored. The physicochemical and structural properties of yogurts with varying concentrations of $\beta$-glucan were determined, and a correlation with the product's sensory perception was attempted.

\section{MATERIALS AND METHODS}

\section{Materials}

Dried skimmed cow milk powder (Marvel, Premier Foods Group Ltd., London, UK) was obtained from a Tesco supermarket (Aberdeen, UK). Insoluble (1/3)-(1/6)- $\beta$-glucan powder made from brewer's yeast (Yestimun) was kindly provided by Leiber $\mathrm{GmbH}$ (Bramsche, Germany). Freeze-dried yogurt starter culture containing Lactobacillus bulgaricus and Streptococcus thermophilus (Goat Nutrition Ltd., Ashford, UK) was used to prepare yogurt starter. Phenolphthalein was purchased from Sigma-Aldrich (St. Louis, MO). All reagents used were of analytical grade.

\section{Scanning Electron Microscopy}

Morphological characterization of Yestimun powder by scanning electron microscopy was performed according to the method of Limberger-Bayer et al. (2014) with some modifications. Yestimun powder samples were sprinkled onto the surface of a carbon tape on a 12.5$\mathrm{mm}$ pin stub. The stub surface was gently blown with an air duster to remove unattached $\beta$-glucan powder. The samples were then made electrically conductive by coating with a thin layer of gold-palladium using a Quorum Q150 ES sputter coater (Quorum Technologies Ltd., East Sussex, UK). The specimens were then imaged at an accelerating voltage of $10 \mathrm{kV}$ using a Zeiss EVO MA10 scanning electron microscope (Carl Zeiss Ltd., Cambridge, UK).

\section{Yogurt Mix Preparation}

Five samples of yogurt were prepared, including a skimmed yogurt control along with yogurts containing varying concentrations of Yestimun powder $(0.2$, $0.4,0.6$, and $0.8 \% \mathrm{wt} / \mathrm{wt}$ ). Up to $1 \mathrm{~kg}$ of yogurt mix was made for each sample using milk powder, filtered water, freshly prepared yogurt starter, and Yestimun powder. Yogurt starter was prepared by dissolving the freeze-dried culture $(5 \mathrm{~g})$ in $840 \mathrm{~g}$ of water and adding $155 \mathrm{~g}$ of dried skimmed cow milk powder $(0.5$ $\mathrm{g}$ of lactic culture/100 $\mathrm{g}$ of milk). The recipe for all samples included $16 \%$ (wt/wt) of dried milk powder and 3\% (wt/wt) of yogurt starter. Yestimun powder was added to the samples according to the different percentages $(0.2-0.8 \% \mathrm{wt} / \mathrm{wt})$, and the water content was adjusted accordingly. Yogurt mixes (milk powder, water, and Yestimun powder if applicable) were heated to $80^{\circ} \mathrm{C}$ for $10 \mathrm{~min}$ and then immediately cooled to a temperature of approximately $45^{\circ} \mathrm{C}$. This was followed by the addition of $30 \mathrm{~g}$ of yogurt starter to the mixes. Samples were then poured in a sterile container and placed in a yogurt fermenter (Lakeland, Aberdeen, UK) set at $44^{\circ} \mathrm{C}$. A portable food and dairy $\mathrm{pH}$ meter (Hanna Instruments Ltd., Leighton Buzzard, UK) was used to measure the changes in $\mathrm{pH}$ of the samples during fermentation on an hourly basis until a $\mathrm{pH}$ of 4.5 was reached. At the end of the fermentation process, samples were gently stirred and stored at $4^{\circ} \mathrm{C}$ overnight until further analysis.

\section{Turbiscan Measurements}

The fermentation process of yogurt samples was monitored using a Turbiscan MA2000 (Formulaction, Ramonville St. Agne, France). The apparatus comprises a detection head equipped with a near-infrared light 
source $(880 \mathrm{~nm})$ that scans the length of the sample, acquiring transmission and backscattering data every $40 \mu \mathrm{m}$. Samples were weighed into a cylindrical borosilicate glass tube ( $25 \mathrm{~mm}$ i.d., $60 \mathrm{~mm}$ high) so that the sample and the vial weighed $40 \mathrm{~g}$ to ensure consistency. The light source scanned the sample at 5-min intervals from top to bottom and measured the percentage of light backscattered or transmitted over a 15 -h period at $42^{\circ} \mathrm{C}$. The coagulation process was evaluated using the Turbiscan stability index (TSI) parameter calculated by Turbisoft Lab 2.2 software (Formulaction, Ramonville St. Agne, France) using the following formulae:

$$
\begin{gathered}
\mathrm{BS}=\frac{1}{\sqrt{\lambda^{*}}}, \\
\lambda^{*}(\varphi, d)=\frac{2 d}{3 \varphi(1-g) Q s,} \\
\mathrm{TSI}=\sqrt{\frac{\sum_{i=1}^{n}\left(\chi^{i}-\chi B S\right)^{2}}{n-1}},
\end{gathered}
$$

where $\lambda^{*}$ is the photon transport mean free path in the analyzed dispersion, $\varphi$ is the volume fraction of particles, $d$ is the mean diameter of particles, $g$ and $Q s$ are the optical parameters given by the Mie theory, $\chi^{i}$ is the average backscattering for each minute of measurement, $\chi B S$ is the average $\chi i$, and $n$ is the number of scans.

\section{Gross Nutrient Composition}

Energy, moisture, ash, fat, carbohydrates, total sugars, and dietary fiber in the samples were determined according to the standard AOAC (1990) official methods. Protein content was determined by combustion according to the Dumas principle and calculation of the $\mathrm{CP}$ content. Carbohydrates were determined by subtracting the sum of moisture, protein, fat, and ash percentages from 100\%. Quantification of the $\beta$-glucan content $(56 \% \mathrm{wt} / \mathrm{wt})$ of the Yestimun powder was calculated using the enzymatic yeast $\beta$-glucan kit (Megazyme, Co. Wicklow, Ireland).

\section{Color Analysis}

Color properties were determined with a Konica Minolta CR1 10 colorimeter (Konica Minolta Solutions Ltd., Basildon, UK) as described by Corradini et al. (2014). The color parameters L* (lightness), a* (red/greenness), and $\mathrm{b}^{*}($ yellow/blueness) of the yogurt samples were evaluated according to the International Commission on Illumination (CIE) $\mathrm{L}^{*} \mathrm{a}^{*} \mathrm{~b}^{*}$ system.

\section{Titratable Acidity Measurement}

A portable food and dairy $\mathrm{pH}$ meter (Hanna Instruments Ltd., Leighton Buzzard, UK) was used to measure the changes in $\mathrm{pH}$ of the samples during fermentation on an hourly basis. The titratable acidity (TA) of the yogurt samples was measured according to the AOAC titration method (AOAC International, 1999) using a Stuart digital burette BT50 (Cole-Palmer, Hanwell London, UK). Briefly, $9.0 \mathrm{~g}$ of yogurt sample was diluted with equal parts Milli-Q water (Millipore, Billerica, MA), and $0.1 M \mathrm{NaOH}$ was used for titration using phenolphthalein as an indicator. The TA was expressed as percentage lactic acid as follows:

$$
\text { lactic acid }(\%)=\mathrm{V} \times 0.009 / \mathrm{W} \times 100,
$$

where $\mathrm{V}$ is the volume of $0.1 \mathrm{M} \mathrm{NaOH}(\mathrm{mL})$ and $\mathrm{W}$ is the weight of yogurt $(\mathrm{g})$.

\section{Texture Analysis}

Texture measurements of yogurt were performed using a CT3 Texture Analyzer (Brookfield Engineering Laboratories Inc., Middleboro, MA) and a cylindrical mesh probe (TA-MP) suitable for yogurt measurements. Data were recorded using Texture Proc CT V1.3 Build 15 software (Brookfield Engineering Laboratories Inc.). Yogurt samples $(200 \mathrm{~g})$ were tested in $250-\mathrm{mL}$ Corning polypropylene cone beakers (Sigma-Aldrich, St. Louis, $\mathrm{MO})$ using the following compression test setting: target distance $=30.0 \mathrm{~mm}$; trigger load $=10 \mathrm{~g}$; test speed $=1.00 \mathrm{~mm} / \mathrm{s} ;$ return speed $=1.00 \mathrm{~mm} / \mathrm{s}$ (Dai et al., 2016). The parameters determined were hardness, total work done, adhesive force, and adhesiveness.

\section{Apparent Viscosity}

Apparent viscosity was determined at $4^{\circ} \mathrm{C}$ using a rotational viscometer (Cole-Palmer Instrument Co. Ltd., London, UK) equipped with an R2 spindle at a speed of $60 \mathrm{rpm}$ (Seo et al., 2009). Two hundred grams of each sample was thoroughly mixed in $250-\mathrm{mL}$ Corning polypropylene cone beakers (height $=8 \mathrm{~cm}$; radii of the circular ends $=4$ and $3 \mathrm{~cm}$, respectively), and the spindle was lowered to the immersion mark located on the spindle shaft. The readings were recorded at the 15 th second of the measurement period as millipascal seconds (mPas.s). 


\section{Syneresis}

Syneresis was measured using the drainage method used by Dai et al. (2016). Approximately $25 \mathrm{~g}$ of yogurt sample was weighed on a $2-\mathrm{V}$ folded filter paper (qualitative, catalog no. 1202-185; Whatman, Maidstone, UK) and placed on the top of a funnel. Syneresis of whey was measured by gravity at $4^{\circ} \mathrm{C}$ for $120 \mathrm{~min}$ in a volumetric flask, and the syneresis value was calculated as the percentage weight of whey collected in a flask divided by the initial weight of the yogurt sample.

\section{Microscopic Structures}

Microscopic images of the yogurt samples containing Yestimun powder were captured by confocal laser scanning microscopy according to the method of Skytte et al. (2015) with modifications. Images were obtained with a Carl Zeiss LSM 710 inverted confocal microscope (Carl Zeiss Ltd., Cambridge, UK). High-purity calcofluor fluorescent stain (Megazyme, Co. Wicklow, Ireland) was used for staining the $\beta$-glucan in yogurt (Kivelä et al., 2009). Samples were gently stirred, and $20 \mu \mathrm{L} / \mathrm{L}$ of calcofluor in $100 \mathrm{~m} N$ sodium carbonate buffer was added at a ratio of 1:1 ( $\mathrm{vol} / \mathrm{vol})$. The mixtures were pipetted onto microscope glass slides, sealed with a cover slip, and allowed to rest for $5 \mathrm{~min}$ at room temperature. Sample micrographs were captured using a $40 \times$ oil immersion objective. Calcofluor was excited at $405 \mathrm{~nm}$, and the emission signal was collected at 467 $\mathrm{nm}$. Images were captured at a resolution of $1,024 \times$ 1,024 pixels.

\section{Consumer Test}

A total of 40 consumers (untrained; 10 male and 30 female; 22 aged 18-30 yr, 8 aged 31-45 yr, and 10 aged 46-60 yr) consisting of students and staff of the University of Aberdeen were recruited and instructed on how to perform sensory evaluation. Most panelists (32/40) were regular consumers of dairy products (consume yogurt at least twice a week), and all declared no food allergies or lactose intolerance. The evaluation of the yogurt samples was performed at the Human Nutrition Unit of Rowett Institute and aimed to assess the degree of liking based on specific sensory attributes (Perina et al., 2015). Yogurt samples (20 g) were marked with 3 -digit codes and presented in white plastic cups. Order of sampling was randomized for each panelist, and water was served between tasting samples. For each sample (control and $0.8 \%$ Yestimun powder), the participants were asked to rate their liking of its appearance, flavor, texture, and aftertaste and overall liking on 9-box structured hedonic scales (from 1 = "I dislike extremely" to $9=$ "I like it extremely") as described by Pimentel et al. (2013).

\section{Statistical Analysis}

Results are expressed as mean \pm standard deviation of 3 replicates (each replicate corresponds to a different batch). Statistical analysis of the data was performed using the statistical software SPSS Statistics 24.0 (SPSS Inc., Chicago, IL). Data were analyzed by ANOVA and Student's $t$-test, and significant differences $(P<0.05)$ were detected by Scheffé's post hoc test.

\section{RESULTS AND DISCUSSION}

\section{Scanning Electron Microscopy}

The morphology of the Yestimun $\beta$-glucan powder was observed by scanning electron microscopy (Figure 1). The scanning electron microscopy images demonstrated the relatively irregular particle size of $\beta$-glucan particles. The formation of aggregates between $\beta$-glucan particles is also observed (Hunter et al., 2002). Scanning electron microscopy analysis illustrated the ridge-like nature of the $\beta$-glucan, with the smooth surface and undulated edges being displayed. The native microstructure of $\beta$-glucan particles is retained as indicated by the oval to elliptical shape of the granular particles.

\section{TSI and Changes in pH During the Fermentation Process}

Turbiscan analysis monitors the fermentation process in real time and provides insight into the gelation process as a result of yogurt formation. The kinetics of flocculation are calculated based on the backscattering or transmission intensities from the middle of the sample over time. Figure 2 shows the TSI for the yogurt samples recorded over a 15-h period, which highlights the 2 different regimens of the backscattering process. The first part of the curve, which shows a gradual incline up to approximately $2 \mathrm{~h}$, is where the backscattering levels increase due to the onset and evolution of the coagulation process. The highest point on the curve, also known as the gelation point, indicates the formation of the jellified network and is evident by the relatively stable backscattering levels. Figure 2B suggests that yogurt samples fortified with Yestimun $\beta$-glucan powder show a steep increase in TSI compared with the control sample. This indicates that the process of yogurt formation occurs at a faster rate in the presence of $\beta$-glucan powder. This finding is in agreement with the $\mathrm{pH}$ readings that were recorded hourly during the fermentation of the yogurt samples (Figure 2A). 
The $\mathrm{pH}$ of samples that contained Yestimun powder decreased at a faster rate than the control. The $\mathrm{pH}$ readings during the fermentation process showed that all the samples fortified with $\beta$-glucan reached the end point $(\mathrm{pH} 4.5)$ after exactly $3 \mathrm{~h}$ regardless of the amount of Yestimun powder, whereas the same levels of acidity were recorded after $4 \mathrm{~h}$ for the control. This finding has important economic implications for the dairy industry because reduced fermentation times can accelerate processing and hence reduce the cost of production. Production costs may be further reduced if efficient methods for the production of $\beta$-glucan from spent brewer's yeast can be developed for the utilization of this by-product of food processing as a valuable functional ingredient in various food formulations. A few studies have demonstrated that the supplementation of fermented dairy products with a range of dietary fibers including $\beta$-glucan affect the growth rates and activities of lactic acid bacteria species (Bruno et al., 2002; Özer et al., 2005; Donkor et al., 2007). The incorporation of dietary fiber is likely to have a prebiotic effect on the lactic acid bacteria present in the starter culture, which increases their growth kinetics and results in shorter
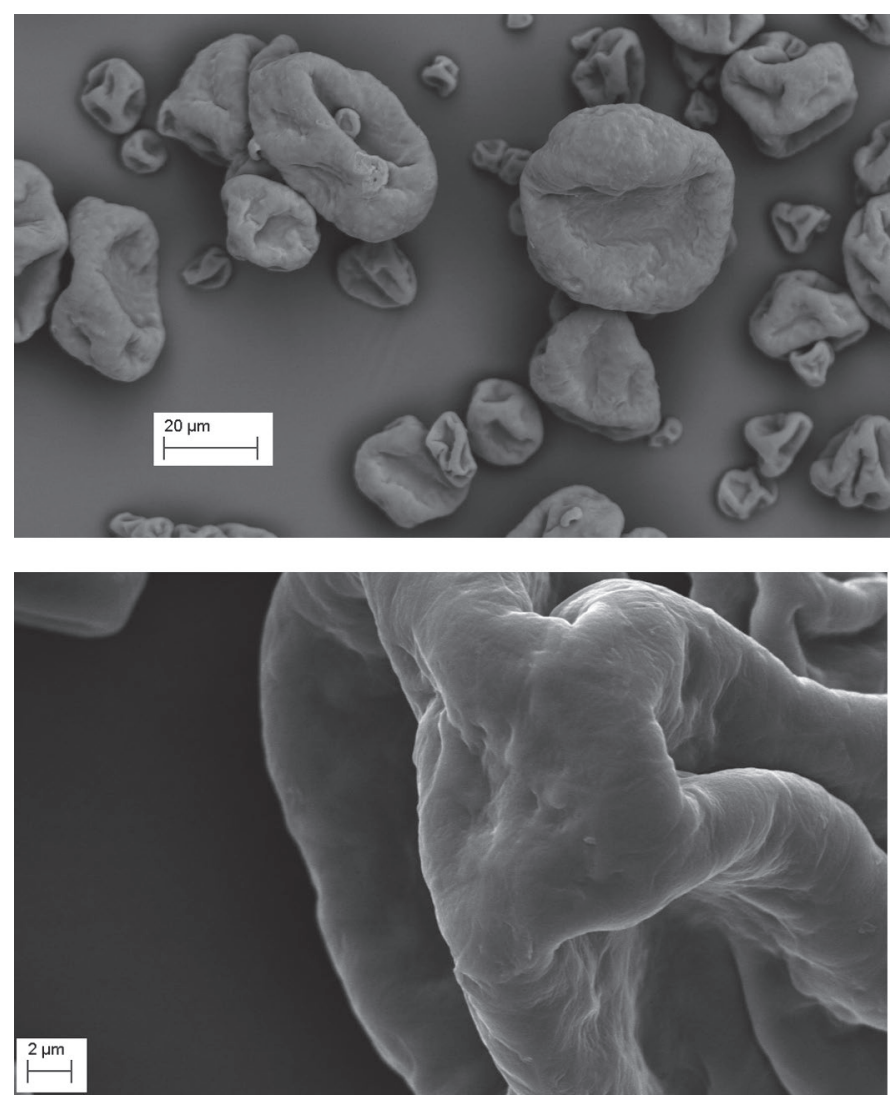

Figure 1. Scanning electron microscopy images for commercially powdered $\beta$-glucan. fermentation times (Ramchandran and Shah, 2008). Preliminary analysis carried out in our laboratory suggests that Yestimun powder can be used as the sole source of nutrients for the growth and reproduction of a few bacterial species present in the human gut, including lactic acid (data not shown). Thus, it is likely that the inclusion of $\beta$-glucan from yeast favors the growth kinetics of the fermenting bacteria; as a result, lactic acid production is increased, leading to a faster $\mathrm{pH}$ development. Furthermore, the fortification of yogurt with $\beta$-glucan may increase the amount of organic acids such as lactic and propionic acid produced during the fermentation process (Vasiljevic et al., 2007). Further investigations are required to elucidate the effect of Yestimun powder on the viability of lactic acid bacteria species, particularly L. bulgaricus and Strep. thermophilus used in this study.

\section{Chemical Composition and Caloric Values}

Proximate analysis is used to determine different macronutrients that are broken down into categories by means of common chemical properties. The proximate analysis and caloric values of the yogurt samples are presented in Table 1. The AOAC method used for the determination of total dietary fiber is an enzymaticgravimetric procedure (Dhingra et al., 2012). Noticeable changes were observed with the dietary fiber levels in the samples. Not surprisingly, there was an increase in the fiber that correlated with the percentage of $\beta$-glucan powder added to the samples. There was a decrease in the moisture content, which corresponds to the replacement of water from the recipe with varying amounts of Yestimun powder. The sodium and fat levels were the same for all samples, with a reading of $<0.1 \mathrm{~g} / 100 \mathrm{~g}$. Protein and carbohydrate levels remained unaffected, whereas there was an increase in caloric values by 2 $\mathrm{kcal} / 100 \mathrm{~g}$ between the control and the sample with the highest $\beta$-glucan powder concentration.

\section{Microscopic Structure}

The microstructure of protein networks in yogurts defines important physical properties of the yogurt that affect product quality. Confocal scanning laser microscopy provides valuable information on the architecture of the network formed in structurally complex food matrices and has become a standard imaging technique for fermented dairy products such as yogurt (Skytte et al., 2015). Confocal electron micrographs of the structure of yogurt samples (Figure 3) were obtained after $1 \mathrm{wk}$ of storage at $4^{\circ} \mathrm{C}$. All the yogurt samples showed homogeneous structures containing relatively small se- 

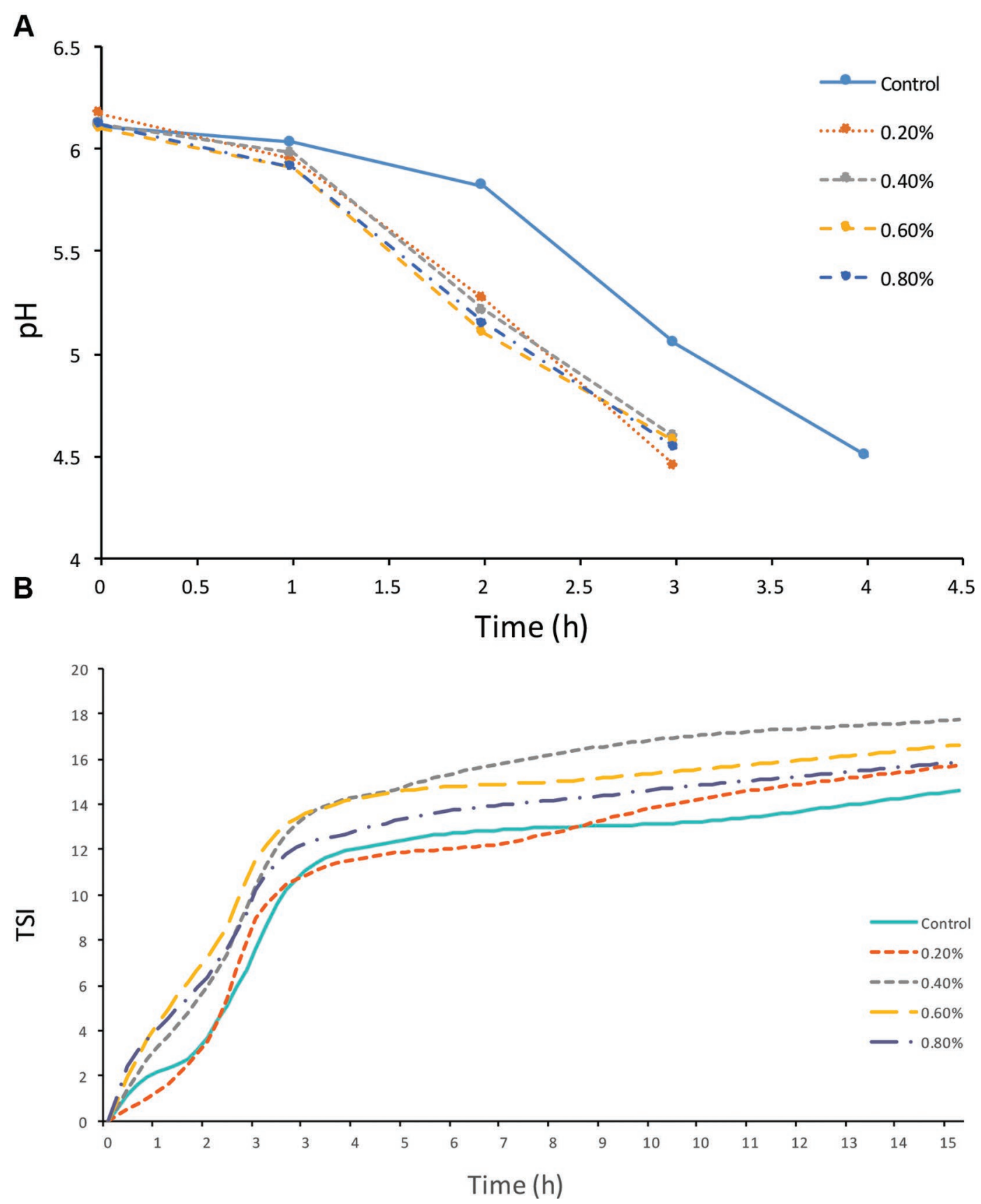

Figure 2. Effect of $\beta$-glucan addition on the fermentation process of yogurts monitored by (A) pH and (B) the Turbiscan stability index (TSI). Color version available online.

rum pores. The fluorescent areas are indicative of the presence of $\beta$-glucan in the yogurt. As shown in Figure 3A through E, the control sample did not display any fluorescent features, whereas increasing the amount of Yestimun in the recipe resulted in a considerable increase in the number and size of clusters of $\beta$-glucan aggregates within the yogurt sample. The shape of the clusters is spherical with a diameter of $>20 \mu \mathrm{m}$ for samples fortified with 0.4 to $0.8 \%$ Yestimun powder. The structures observed could be related to some sensory features of the different yogurt formulations. The protein network formation as a result of casein aggregation seems to be unaffected by the incorporation of $\beta$-glucan. This is attributed to the low water solubility of the $\beta$-glucan from baker's yeast, which has a structure consisting of long linear chains of glucose 

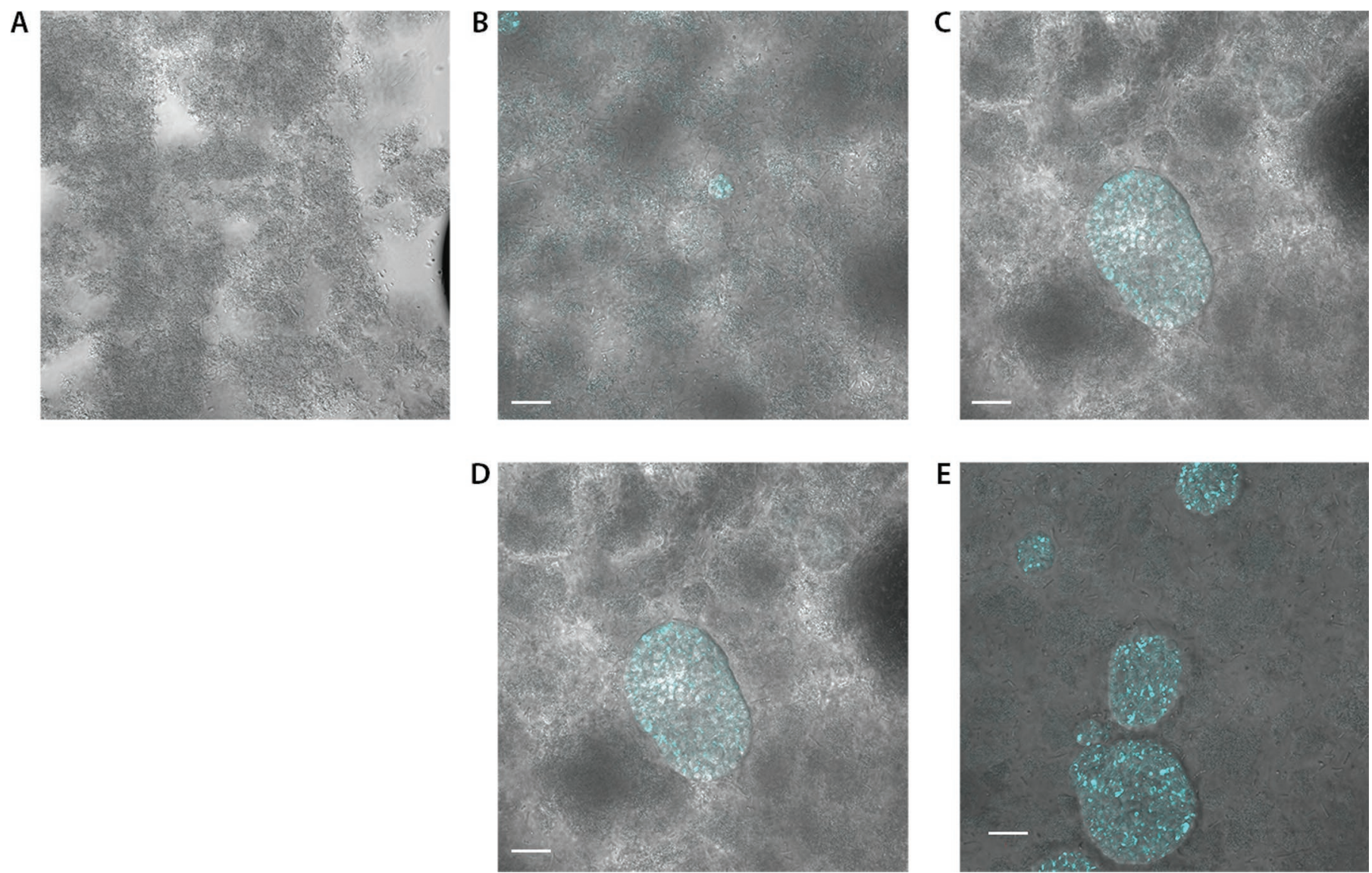

Figure 3. Confocal laser scanning microscopy of yogurt samples stained with the fluorescent dye Calcofluor: (A) yogurt control, (B) $0.2 \%$, (C) $0.4 \%$, (D) $0.6 \%$, and (E) $0.8 \% \beta$-glucan. Scale bar is $20 \mu \mathrm{m}$. Color version available online.

with $\beta$ - $(1 \rightarrow 3)$ as well as $(1 \rightarrow 6)$ linkages (Gardiner and Carter, 2000).

\section{Physicochemical Properties}

Table 3 shows the syneresis, apparent viscosity, TA, and color of control yogurts and yogurts fortified with $\beta$-glucan. The majority of the physicochemical properties of yogurts were not significantly affected by the addition of Yestimun powder. Syneresis denotes the expulsion of liquid whey from yogurt due to contraction of the gel (Walstra, 1993) and is considered a primary defect often related to consumer acceptability. The phenomenon is typically associated with a loose casein micelle network resulting in a weak gel incapable of retaining water. There was a nonsignificant $(P>$ $0.05)$ decrease in the syneresis percentage with increasing $\beta$-glucan amount incorporated in the recipe. This

Table 1. Proximate analysis of yogurts containing varying concentrations of $\beta$-glucan

\begin{tabular}{lccccc}
\hline & \multicolumn{5}{c}{$\beta$-glucan $(\% \mathrm{wt} / \mathrm{wt})$} \\
\cline { 2 - 6 } Nutritional analysis & 0 & 0.2 & 0.4 & 0.6 & 0.8 \\
\hline Energy (kcal/100 g) & 62 & 62 & 63 & 63 & 64 \\
Protein (g/100 g) & 6.51 & 6.44 & 6.63 & 6.29 & 6.53 \\
Ash (g/100 g) & 1.31 & 1.32 & 1.32 & 1.32 & 1.33 \\
Moisture (g/100 g) & 83.18 & 83.01 & 82.72 & 82.63 & 82.37 \\
Carbohydrates (g/100 g) & 9.00 & 9.02 & 8.90 & 9.19 & 8.93 \\
Total sugars (g/100 g) & 7.31 & 7.13 & 7.31 & 7.20 & 7.30 \\
Sodium (g/100 g) & $<0.1$ & $<0.1$ & $<0.1$ & $<0.1$ & $<0.1$ \\
Dietary fiber (g/100 g) & $<0.1$ & 0.20 & 0.43 & 0.57 & 0.84 \\
Fat (g/100 g) & $<0.1$ & $<0.1$ & $<0.1$ & $<0.1$ & $<0.1$ \\
\hline
\end{tabular}


Table 2. Syneresis, apparent viscosity, titratable acidity (TA), and color of yogurts fortified with $\beta$-glucan (mean \pm SD)

\begin{tabular}{|c|c|c|c|c|c|c|}
\hline$\beta$-glucan (g/100 g) & Syneresis (\%) & Viscosity $(\mathrm{Pa} \cdot \mathrm{s})$ & TA $(\%)$ & \multicolumn{3}{|c|}{ Color $^{1}$} \\
\hline$\overline{0.0}$ & $12.06 \pm 1.5^{\mathrm{a}}$ & $11.61 \pm 2.2^{\mathrm{a}}$ & $1.73 \pm 0.07^{\mathrm{a}}$ & $46.00 \pm 3.2^{\mathrm{a}}$ & $-1.10 \pm 0.1^{\mathrm{a}}$ & $7.03 \pm 0.3^{\mathrm{a}}$ \\
\hline 0.4 & $10.89 \pm 2.4^{\mathrm{a}}$ & $11.18 \pm 1.7^{\mathrm{a}}$ & $1.60 \pm 0.11^{\mathrm{a}}$ & $47.78 \pm 0.8^{\mathrm{a}}$ & $-0.97 \pm 0.1^{\mathrm{a}}$ & $7.20 \pm 0.3^{\text {ac }}$ \\
\hline 0.6 & $10.77 \pm 0.9^{\mathrm{a}}$ & $11.80 \pm 2.1^{\mathrm{a}}$ & $1.69 \pm 0.12^{\mathrm{a}}$ & $45.93 \pm 2.4^{\mathrm{a}}$ & $-0.68 \pm 0.0^{\mathrm{b}}$ & $7.76 \pm 0.3^{\mathrm{bc}}$ \\
\hline 0.8 & $10.29 \pm 1.9^{\mathrm{a}}$ & $10.75 \pm 0.6^{\mathrm{a}}$ & $1.73 \pm 0.17^{\mathrm{a}}$ & $45.83 \pm 2.0^{\mathrm{a}}$ & $-0.60 \pm 0.1^{\mathrm{b}}$ & $7.65 \pm 0.3^{\mathrm{ac}}$ \\
\hline
\end{tabular}

${ }^{\mathrm{a}-\mathrm{c}}$ Means within a column with different superscripts are significantly different $(P<0.05)$.

${ }^{1} \mathrm{~L}^{*}=$ lightness; $\mathrm{a}^{*}=$ red/greenness; $\mathrm{b}^{*}=$ yellow/blueness.

could be attributed to the distribution of the $\beta$-glucan particles within the yogurt matrix combined with their known ability to bind water and possess a high water retention capacity (Dhingra et al., 2012). Comparatively, other studies (Vasiljevic et al., 2007; Singh et al., 2012) suggest that the addition of oat and barley $\beta$-glucan resulted in increased syneresis exhibited by the yogurt samples. This effect was attributed to the formation of a weak gel that was incapable of retaining water due to the interference of the long polysaccharide molecules with the casein micelle network during gel formation (Lucey et al., 1998). This disparity in the findings could be attributable to the structural differences between soluble and insoluble $\beta$-glucan molecules.

Viscosity measures the resistance of a fluid that is being deformed by either shear stress or tensile stress. Yogurt displays a non-Newtonian shear-thinning behavior, which means that viscosity decreases with an increase in shear rate (Lambo et al., 2005). In this study, the apparent viscosity of the yogurt samples was not significantly affected $(P>0.05)$ by the addition of Yestimun powder. Previous studies have shown that apparent viscosity of yogurt was significantly increased with the addition of inulin (Balthazar et al., 2015). This effect was attributed to the ability of the watersoluble polysaccharide to retain water and extensively interact with milk proteins, leading to an increase in the molar mass. In this case, the low water solubility of $\beta$-glucan and the formation of small clusters within the yogurt matrix prevented the formation of an extended structure capable of entrapping large amounts of water.
The TA of the yogurt was also not significantly $(P>$ $0.05)$ affected by the addition of $\beta$-glucan, with values ranging from 1.60 to 1.73 (Table 2). Similar results were reported for yogurt fortified with oat fiber (FernándezGarcía et al., 1998), which suggests that the metabolic activity of the lactic acid bacteria and thus the production of organic acids during the fermentation process was not affected by the addition of $\beta$-glucan from yeast.

The color attributes of yogurt samples are displayed in Table 2. The $\mathrm{L}^{*}$ value represents lightness (100) and blackness (0), which is considered the most important determinant of the perceived appearance of yogurt. The $a^{*}$ values represent red/green (positive/negative) hues of the yogurt samples, and $b^{*}$ values represent yellow/blue (positive/negative) hues (Dai et al., 2016). No significant differences $(P>0.05)$ were detected in the $\mathrm{L}^{*}$ parameter of the yogurt, which highlighted that the whiteness of the samples was similar regardless of $\beta$-glucan addition. The $\mathrm{a}^{*}$ (negative) and $\mathrm{b}^{*}$ (positive) parameters indicated that all samples displayed greenish and yellowish hues. The $\mathrm{a}^{*}$ values (redness) decreased, whereas the $b^{*}$ values (yellowness) increased with increasing levels of $\beta$-glucan in the yogurt mix. The effects on the $a^{*}$ and $b^{*}$ parameters show that there is a $\beta$-glucan concentration-dependent effect. The findings of the present study are similar to previous studies of yogurt fortification with konjac glucomannan (Dai et al., 2016). The increase in the yellowish hue was justified as being the product of Maillard reaction in milk during heating. Hashim et al. (2009) also reported that the yellowness of yogurt depends on the levels of

Table 3. Texture attributes of stirred yogurt samples

\begin{tabular}{|c|c|c|c|c|c|}
\hline \multirow[b]{2}{*}{ Textural property } & \multicolumn{5}{|c|}{$\beta$-glucan (g/100 g) } \\
\hline & 0 & 0.2 & 0.4 & 0.6 & 0.8 \\
\hline Hardness (g) & $26.00 \pm 5.2^{\mathrm{a}}$ & $22.20 \pm 6.4^{\mathrm{a}}$ & $23.20 \pm 5.0^{\mathrm{a}}$ & $27.60 \pm 4.6^{\mathrm{a}}$ & $31.00 \pm 4.9^{\mathrm{a}}$ \\
\hline Total work done $(\mathrm{mJ})$ & $6.00 \pm 1.0^{\mathrm{a}}$ & $5.36 \pm 1.5^{\mathrm{a}}$ & $5.66 \pm 1.4^{\mathrm{a}}$ & $6.66 \pm 1.2^{\mathrm{a}}$ & $7.40 \pm 1.1^{\mathrm{a}}$ \\
\hline Adhesive force (g) & $26.00 \pm 3.7^{\mathrm{a}}$ & $25.20 \pm 6.5^{\mathrm{a}}$ & $26.40 \pm 3.2^{\mathrm{a}}$ & $28.60 \pm 4.0^{\mathrm{a}}$ & $31.60 \pm 2.8^{\mathrm{a}}$ \\
\hline Adhesiveness (mJ) & $8.38 \pm 1.3^{\mathrm{a}}$ & $8.12 \pm 2.3^{\mathrm{a}}$ & $8.32 \pm 1.0^{\mathrm{a}}$ & $9.22 \pm 1.5^{\mathrm{a}}$ & $10.12 \pm 0.9^{\mathrm{a}}$ \\
\hline
\end{tabular}

${ }^{a}$ Means within a row with different superscripts are significantly different $(P<0.05)$. 
dietary fiber present and, as a result, yogurt color is dependent on the color of the fiber source.

\section{Texture Analysis}

Textural characteristics of foods are related to consumer liking and determine to a large extent the acceptance of the product. Hardness denotes the force required to attain a given deformation, whereas adhesive force is the force required to "pull" the sample from the probe. Adhesiveness is a good indicator of the sample's spoonability (viscosity) and relates to the work necessary to overcome the attractive forces between a substance and the surface of other materials. Total work done is dependent on the strength of the internal bonds within a product and is often related to its consistency. The yogurt gels formed with $\beta$-glucan levels up to $0.4 \%$ were similar or lower compared with the control as determined by all textural parameters. Further addition of Yestimun powder $(>0.6 \%)$ resulted in increased textural properties, and the effect was concentration dependent. The greatest difference was observed with the hardness and adhesive force parameters between the control and the $0.8 \%$ yogurt sample. Although there was a clear incremental effect at the highest $\beta$-glucan concentration for all textural attributes, these were not at a significant level $(P>0.05)$. Similar findings were reported by Singh et al. (2012), who demonstrated that the addition of purified oat $\beta$-glucan at levels higher than $0.3 \%$ resulted in noticeable differences in the textural characteristics of set-style yogurts. The increased hardness may be attributed to the increased solid nonfat content of the recipe and the decreased moisture levels (Table 1) following the addition of the Yestimun powder. Adhesiveness was not significantly $(P>0.05)$ different for all the samples compared with the control, which is in line with the apparent viscosity measurements. The increased consistency of the sample containing $0.8 \%$ Yestimun powder as indicated by the total work done parameter may be related to the decreased levels of syneresis exhibited at this concentration of $\beta$-glucan.

\section{Sensory Evaluation}

The development of fermented milk products with the inclusion of novel ingredients is likely to affect the organoleptic properties of the food. Thus, evaluating the sensory properties of the newly developed yogurt is essential for optimizing the recipe and determines product acceptability and consumer liking (Janiaski et al., 2016). A common approach adopted by the dairy industry for new product development is the use of descriptive analysis (Torres et al., 2017). This method uses a panel to identify and quantify the intensity of specific sensory attributes that are considered important for product profiling and acceptability. Descriptive sensory methodologies based on consumer perceptions can be used to obtain a generalized sensory profiling of the product but has certain limitations (Cruz et al., 2013). A large number of participants (>100) is required, and more specific sensory attributes can be assessed only by trained panelists. In this study, a consumer test was performed to allow the sensory description of the reformulated product and obtain useful information based on hedonic judgements (Oliveira et al., 2017). The sample with the highest $\beta$-glucan concentration $(0.8 \% \mathrm{wt} / \mathrm{wt})$ was selected for sensory profiling because instrumental analysis indicated that it was more distinctively different from the control than any other sample. Table 4 shows the sensory evaluation scores (nonspecific attributes) for the control and 0.8\% yogurt sample. The sensory attributes measured were not significantly different $(P>0.05)$ between the 2 samples, and results are in accordance with the instrumental analysis. Overall, the control yogurt received the best scores in all attributes evaluated, suggesting that the addition of Yestimun powder decreased the sensory performance of the yogurt mix. The mean acceptability scores for the characteristics measured for the control yogurt ranged from 6.0 to 6.7 , which corresponds to "like slightly" on the 1- to 9-point hedonic scale. The yogurt sample fortified with the $0.8 \% \beta$-glucan had scores ranging from 4.7 to 6.5 , which is equivalent to "dislike slightly," "neither like nor dislike," and "like slightly." The flavor and the aftertaste of the yogurt fortified with $\beta$-glucan had the lowest scores $(<5.0)$, which may at least partially account for the overall liking score obtained for the product. Sensory analysis revealed no major differences in terms of appearance, which is in agreement with the results obtained from the color measurements $\left(\mathrm{L}^{*}\right)$. The slightly higher texture score of the control may reflect the increased hardness of the yogurt containing $\beta$-glucan, as indicated by the instrumental analysis. Considering that yogurts were prepared using skim milk powder and that the highest $\beta$-glucan concentration was selected for sensory testing, it is reasonable that any scores higher than 5 are considered acceptable. The relatively small number of participants (40) is the main limitation of the current study. However, the preliminary sensory data obtained can be used for the formulation stages of food matrices that contain $\beta$-glucan from spent brewer's yeast.

\section{CONCLUSIONS}

The current study demonstrated that the fortification of yogurt with $\beta$-glucan can greatly affect gel network 
Table 4. Nonspecific sensory attributes of stirred yogurt samples fortified with $\beta$-glucan (mean $\pm \mathrm{SD}$ )

\begin{tabular}{lccccc}
\hline Treatment & Appearance & Flavor & Texture & Aftertaste & Overall liking \\
\hline Control & $6.7 \pm 1.5^{\mathrm{a}}$ & $6.2 \pm 1.7^{\mathrm{a}}$ & $6.1 \pm 1.6^{\mathrm{a}}$ & $6.0 \pm 1.6^{\mathrm{a}}$ & $6.2 \pm 1.8^{\mathrm{a}}$ \\
$0.8 \% \beta$-glucan & $6.5 \pm 1.6^{\mathrm{a}}$ & $4.9 \pm 1.9^{\mathrm{a}}$ & $5.4 \pm 1.7^{\mathrm{a}}$ & $4.7 \pm 1.7^{\mathrm{a}}$ & $5.0 \pm 1.8^{\mathrm{a}}$ \\
\hline
\end{tabular}

${ }^{a}$ Means within a column with different superscripts are significantly different $(P<0.05)$.

formation, resulting in a substantial decrease in the fermentation time. The TSI and hourly $\mathrm{pH}$ results both confirmed that the fortified yogurt took approximately $1 \mathrm{~h}$ less to reach the end-point $\mathrm{pH}$ of 4.5 compared with the yogurt control. The results indicated that there were no significant differences between the physicochemical properties assessed; however, there was a significant difference between the $\mathrm{a}^{*}$ and $\mathrm{b}^{*}$ parameters of the yogurt control and yogurts fortified with 0.6 and $0.8 \% \beta$-glucan. The addition of the $\beta$-glucan had an incremental effect on the textural properties that were more detectable at $0.8 \%$ concentration. Results obtained from instrumental analysis are in agreement with the sensory analysis. Despite the fact that the addition of Yestimun powder had an adverse effect on the overall liking of the yogurt, no significant differences were identified between the sensory evaluation scores for the yogurt control and the yogurt fortified with $0.8 \% \beta$-glucan. Further work is required to investigate the effect of purified $\beta$-glucan from yeast on the viability of lactic acid bacteria.

\section{ACKNOWLEDGMENTS}

This work is part of the Strategic Research Programme 2016-2021 and is funded by the Scottish Government's Rural and Environment Science and Analytical Services Division. Microscopy was performed in the Microscopy and Histology Core Facility at the University of Aberdeen. The authors declare that there are no conflicts of interest.

\section{REFERENCES}

Ahmad, A., F. M. Anjum, T. Zahoor, H. Nawaz, and S. M. R. Dilshad. 2012. Beta glucan: A valuable functional ingredient in foods. Crit. Rev. Food Sci. Nutr. 52:201-212.

Aimanianda, V., C. Clavaud, C. Simenel, T. Fontaine, M. Delepierre, and J.-P. Latgé. 2009. Cell wall $\beta$-(1,6)-glucan of Saccharomyces cerevisiae. J. Biol. Chem. 284:13401-13412.

AOAC. 1990. Official Methods of Analysis. 15th ed. Association of Official Analytical Chemists, Washington, DC.

AOAC International. 1999. Official Methods of Analysis. Vol. II. 5th rev. AOAC Int., Rockville, MD.

Astrup, A., J. Dyerberg, M. Selelck, and S. Stender. 2008. Nutrition transition and its relationship to the development of obesity and related chronic diseases. Obes. Rev. 9:48-52.

Balthazar, C. F., C. A. Conte-Junior, J. Moraes, M. P. Costa, R. S. L. Raices, R. M. Franco, A. G. Cruz, and A. C. O. Silva. 2016. Physicochemical evaluation of sheep milk yogurts containing different levels of inulin. J. Dairy Sci. 99:4160-4168.
Balthazar, C. F., H. L. A. Silva, R. M. S. Celeguini, R. Santos, G. M. Pastore, C. A. Conte Junior, M. Q. Freitas, L. C. Nogueira, M. C. Silva, and A. G. Cruz. 2015. Effect of galactooligosaccharide addition on the physical, optical, and sensory acceptance of vanilla ice cream. J. Dairy Sci. 98:4266-4272.

Belsito, P. C., M. V. S. Ferreira, L. P. Cappato, R. N. Cavalcanti, V. A. S. Vidal, T. C. Pimentel, E. A. Esmerino, C. F. Balthazar, R. P. C. Neto, M. I. B. Tavares, P. B. Zacarchenco, M. Q. Freitas, M. C. Silva, R. S. L. Raices, G. M. Pastore, M. A. R. Pollonio, and A. G. Cruz. 2017. Manufacture of Requeijão cremoso processed cheese with galactooligosaccharide. Carbohydr. Polym. 174:869-875.

Bruno, A., W. E. V. Lankaputhra, and N. P. Shah. 2002. Growth, viability and activity of Bifidobacterium spp. in skim milk containing prebiotics. J. Food Sci. 67:2740-2744

Chandan, R. C., and K. R. O'Reil. 2006. Ingredients for yogurt manufacture. Pages 217-238 in Manufacturing Yogurt and Fermented Milks. R. C. Chandran and A. Kilara, ed. Blackwell, Ames, IA.

Corradini, S. A., S. G. S. Madrona, J. V. Visentainer, E. G. Bonafe, C. B. Carvalho, P. M. Roche, and I. N. Prado. 2014. Sensorial and fatty acid profile of ice cream manufactured with milk of crossbred cows fed palm oil and coconut fat. J. Dairy Sci. 97:6745-6753.

Cruz, A. G., R. S. Cadena, W. S. Castro, E. A. Esmerino, J. B. Rodrigues, L. Gaze, J. A. F. Faria, M. Q. Freitas, R. Deliza, and H. M. A. Bolini. 2013. Consumer perception of probiotic yogurt: Performance of check all that apply (CATA), projective mapping, sorting and intensity scale. Food Res. Int. 54:601-610.

da Silva Araújo, V. B., A. N. F. de Melo, A. G. Costa, R. H. CastroGomez, M. S. Madruga, E. L. de Souza, and M. Magnani. 2014. Followed extraction of $\beta$-glucan and mannoprotein from spent brewer's yeast (Saccharomyces uvarum) and application of the obtained mannoprotein as a stabilizer in mayonnaise. Int. Food Sci. Emerg. Technol. 23:164-170.

Dai, S., H. Corke, and N. P. Shah. 2016. Utilization of konjac glucomannan as a fat replacer in low-fat and skimmed yogurt. J. Dairy Sci. 99:7063-7074.

Dhingra, D., M. Michael, H. Rajput, and R. T. Patil. 2012. Dietary fiber in foods: A review. J. Food Sci. Technol. 49:255-266.

Donkor, O. N., S. L. I. Nilmini, P. Stolic, T. Vasiljevic, and N. P. Shah. 2007. Survival and activity of selected probiotic organisms in settype yogurt during cold storage. Int. Dairy J. 17:657-665.

EFSA Panel on Dietetic Products, Nutrition, and Allergies. 2011. Scientific opinion on the safety of "yeast $\beta$-glucans" as a novel food ingredient. EFSA J. 9:2137.

FAO/WHO (Food and Agriculture Organization of the United Nations/World Health Organization). 2001. Health and Nutritional Properties of Probiotics in Food Including Powder Milk with Live Lactic Acid Bacteria. FAO/WHO, Rome, Italy.

Fernández-García, E., J. McGregor, and S. Traylor. 1998. The addition of oat fiber and natural alternative sweeteners in the manufacture of plain yogurt. J. Dairy Sci. 81:655-663.

Ferrão, L. L., M. V. S. Ferreira, R. N. Cavalcanti, A. F. A. Carvalho, T. C. Pimentel, R. Silva, E. A. Esmerino, R. P. C. Neto, M. I. B. Tavares, M. Q. Freitas, J. C. V. Menezes, L. M. Cabral, J. Moraes, M. C. Silva, S. P. Mathias, R. S. L. Raices, G. M. Pastore, and A. G. Cruz. 2018. The xylooligosaccharide addition and sodium reduction in requeijão cremoso processed cheese. Food Res. Int. 107:137-147.

Folkenberg, D. M., and M. Martens. 2003. Sensory properties of low fat yoghurts. Part B: Hedonic evaluations of plain yoghurts by consumers correlated to fat content, sensory profile and consumer attitudes. Milchwissenschaft 58:154-157. 
Gardiner, T., and G. Carter. 2000. $\beta$-glucan biological activities: A review (condensed version). GlycoScience 1:1-2.

Granato, D., G. F. Branco, A. G. Cruz, J. A. F. Faria, and N. P. Shah. 2010. Probiotic dairy products as functional foods. Compr. Rev. Food Sci. Food Saf. 9:455-470.

Hashim, I. B., A. H. Khalil, and H. S. Afifi. 2009. Quality characteristics and consumer acceptance of yogurt fortified with date fiber. J. Dairy Sci. 92:5403-5407.

Hill, C., F. Guarner, G. Reid, G. R. Gibson, D. J. Merenstein, B. Pot, L. Morelli, R. B. Canani, H. J. Flint, and S. Salminen. 2014. Expert consensus document: The International Scientific Association for Probiotics and Prebiotics consensus statement on the scope and appropriate use of the term probiotic. Nat. Rev. Gastroenterol. Hepatol. 11:506-514.

Hunter, K. W., R. A. Gault, and R. A. Berner. 2002. Preparation of microparticulate $\beta$-glucan from Saccharomyces cerevisiae for use in immune potentiation. Lett. Appl. Microbiol. 35:267-271.

Janiaski, D. R., T. C. Pimentel, A. G. Cruz, and S. H. Prudencio. 2016. Strawberry-flavored yogurts and whey beverages: What is the sensory profile of the ideal product? J. Dairy Sci. 99:5273-5283.

Kivelä, R., L. Nyström, H. Salovaara, and T. Sontag-Strohm. 2009. Role of oxidative cleavage and acid hydrolysis of oat beta-glucan in modelled beverage conditions. J. Cereal Sci. 50:190-197.

Lam, K.-L., and P. C.-K. Cheung. 2013. Non-digestible long chain beta-glucans as novel prebiotics. Bioact. Carbohydr. Dietary Fibre $2: 45-64$.

Lambo, A. M., R. Oste, and M. E. G. Nyman. 2005. Dietary fiber in fermented oat and barley $\beta$-glucan rich concentrates. Food Chem. 89:283-293.

Limberger-Bayer, V. M., A. De Francisco, A. Chan, T. Oro, P. J. Ogliari, and P. L. M. Barreto. 2014. Barley $\beta$-glucans extraction and partial characterization. Food Chem. 154:84-89.

Lucey, J. A., P. A. Munro, and H. Singh. 1998. Whey separation in acid skim milk gels made with glucono-6-lactone: Effects of heat treatment and gelation temperature. J. Texture Stud. 29:413-426.

Martins, Z. E., M. Erben, A. E. Gallardo, R. Silva, I. Barbosa, O. Pinho, and I. M. P. L. V. O. Ferreira. 2015. Effect of spent yeast fortification on physical parameters, volatiles and sensorial characteristics of home-made bread. Int. J. Food Sci. Technol. 50:1855-1863.

Oliveira, E. W., E. A. Esmerino, B. T. Carr, L. P. F. Pinto, H. L. A. Silva, T. C. Pimentel, H. M. A. Bolini, A. G. Cruz, and M. Q. Freitas. 2017. Reformulating Minas Frescal cheese using consumers perceptions: Insights from intensity scales and check-all-that-apply questionnaires. J. Dairy Sci. 100:6111-6124.

Özer, D., S. Akin, and B. Özer. 2005. Effect of inulin and lactulose on survival of Lactobacillus acidophilus LA-5 and Bifidobacterium bifidum BB-02 in acidophilus-bifidus yoghurt. Food Sci. Technol. Int. 11:19-24.

Perina, N. P., D. Granato, C. Hirota, A. G. Cruz, C. S. B. Bogsan, and M. N. Oliveira. 2015. Effect of vegetal-oil emulsion and passion fruit peel-powder on sensory acceptance of functional yogurt. Food Res. Int. 70:134-141.

Pimentel, T. C., A. G. Cruz, and S. H. Prudencio. 2013. Short communication: Influence of long-chain inulin and Lactobacillus paracasei subspecies paracasei on the sensory profile and acceptance of a traditional yogurt. J. Dairy Sci. 96:6233-6241.

Ramchandran, L., and N. P. Shah. 2008. Effect of addition of Versagel ${ }^{\circledR}$ on microbial, chemical and physical properties of low-fat yogurt. J. Food Sci. 73:M360-M367.

Seo, M. H., S.-Y. Lee, Y. H. Chang, and H. S. Kwak. 2009. Physicochemical, microbial, and sensory properties of yogurt supplemented with nanopowdered chitosan during storage. J. Dairy Sci. 92:5907-5916.

Singh, M., S. Kim, and S. X. Liu. 2012. Effect of purified oat $\beta$-glucan on fermentation of set-style yogurt mix. J. Food Sci. 77:E195E201.

Skytte, J. L., O. Ghita, P. F. Whelan, U. Andersen, F. Møller, A. B. Dahl, and R. Larsen. 2015. Evaluation of yogurt microstructure using confocal laser scanning microscopy and image analysis. J. Food Sci. 80:E1218-E1228.

Thammakiti, S., M. Suphantharika, T. Phaesuwan, and C. Verduyn 2004. Preparation of spent brewer's yeast $\beta$-glucans for potential applications in the food industry. Int. J. Food Sci. Technol. $39: 21-29$

Torres, F. R., E. A. Esmerino, B. T. Carr, L. L. Ferrão, D. Granato, T. C. Pimentel, H. M. A. Bolini, M. Q. Freitas, and A. G. Cruz. 2017. Rapid consumer-based sensory characterization of requeijão cremoso, a spreadable processed cheese: Performance of new statistical approaches to evaluate check-all-that-apply data. J. Dairy Sci. 100:6100-6110.

Tripathi, M. K., and S. K. Giri. 2014. Probiotic functional foods: Survival of probiotics during processing and storage. J. Funct. Foods 9:225-241.

Vasiljevic, T., T. Kealy, and V. Mishra. 2007. Effects of $\beta$-glucan addition to a probiotic containing yogurt. J. Food Sci. 72:C405-C411.

Walstra, P. 1993. The syneresis of curd. Pages 141-191 in Cheese Chemistry, Physics and Microbiology. Vol. 1: General Aspects. P. F. Fox, ed. Springer, Boston, MA.

Willett, W. 2013. Nutritional Epidemiology. Oxford University Press, Oxford, UK

Worrasinchai, S., M. Suphantharika, S. Pinjai, and P. Jamnong. 2006. $\beta$-Glucan prepared from spent brewer's yeast as a fat replacer in mayonnaise. Food Hydrocoll. 20:68-78.

Zhu, F., B. Du, Z. Bian, and B. Xu. 2015. $\beta$-Glucans from edible and medicinal mushrooms: Characteristics, physicochemical and biological activities. J. Food Compos. Anal. 41:165-173.

Zhu, F., B. Du, and B. Xu. 2016. A critical review on production and industrial applications of $\beta$-glucans. Food Hydrocoll. 52:275-288. 